\title{
International influences and Drag: Just a Case of Tucking or Binding?
}

\section{Stephen Farrier.}

\section{Royal Central School of Speech and Drama, University of London.}

In mid-January 2017 Her Upstairs, a London drag bar, pays tribute to David Bowie.1 The lineup includes amongst others: Ruby Wednesday, a drag queen; Adam All, a drag king, tonight appearing with femme, female-identified singer Apple Derrieres; Pi The Mime, a performer working in boylesque cabaret with drag elements; Mynxie Munroe a burlesque performer, and Drastik Measures, another performer who uses drag elements in their act. Ruby Wednesday, who uses both lip synching and singing in their act and who works in both the drag and cabaret scene in the UK, emcees the evening. The bar is run by, amongst others, Meth, a very popular drag queen who has worked internationally, has a global fan base, and has featured in a fly on the wall documentary about drag queens in London, UK. The regular crowd in the venue reflect the range of the performers on stage. Often present are a mist of genders and sexualities (some cis, some trans, some straight, gay, queer, some wearing their identities, literally, on their sleeve) and there is regularly a smattering of drag in the audience. This is a queer crowd, mixed and only partly decipherable to normative looks. On stage, all the acts have their own distinct flavour in relation to gender, sex and sexuality, which is often at the centre of their performances. The acts' look different too and arouse diverse energies, yet despite the performance work appearing different in many ways, at some level, it speaks a similar lexicon. Many of these performers refer to their acts as drag, or burlesque or cabaret - and it is worth noting that the descriptions of the acts above describe the kinds of work present in the bar, rather than any classification the performers declare themselves, that is often more complex. Yet, it begs the question, given as the work and genders are 
diverse, what coheres the performances? Moreover, crucially, how can the work be spoken of and accounted for without crushing the diversity so vital to the heart of this work and community?

The popularity of nights like the one at Her Upstairs is a sign that both kinging and queening have gained popularity in recent years. From world-wide television programmes such as $R u$ Paul's Drag Race (Logo TV), to mentions in recent national newspapers, international websites, blogs and youth programming on the $\mathrm{BBC}$, the performance form appears to be more ever-present.2 As Senelick (2000) has described, drag has kept a presence in performance and popular culture for a very long time. The work of drag has maintained deep roots in popular culture and performance and, as this article notes, serves several functions for the communities in which it most often appears.

Where drag as performance form is written about in academic journals it is most often done so in terms of its relation to the plasticity of gender, the challenges it brings to solidified and stratified visions of gender and in some cases the ways in which it might support at some level powerful patriarchal structures (for example see Bateman 2002, Edgar 2011, Schapiro 2010, Taylor \& Rupp 2005). Certainly there are omissions where drag is not dealt with as a performance form and, crucially, little engagement with how drag performers learn and perfect their skills and craft. This article in part seeks to contribute to the bourgeoning discussion about drag training whilst also maintaining a very direct energy on the ways in which drag is vitally connected to community and popular audiences. These two connected elements have deep implications for how its training is present and how it may be explicated. 
The discussion here looks at the structures that exist in the community that develop and support drag performance, whilst also asking questions about what kings and queens do in their work. So diverse is the range of drag, this discussion focusses on three emblematic UK performers at different stages of their performance careers - all who came to drag performance at different historical times - structured around the development of technology, in particular web 2.0.3 Underlying all this discussion is a look at how traditions of drag training have changed over the past 20 years in relation to technology that has resulted in an internationalisation of the form, which in turn, has an impact on the kind of works produced. Such new structures have resulted in the erosion of certain training traditions and this discussion engages with this a form of politics. Principally, therefore, this paper thinks through the international aspect of its title via the geographical reach and influence of the internet. Though this discussion does not seek to account for drag internationally, that is a much larger task, the discussion deals with the impact of internationally available sources for practitioners to learn about drag.

Starting from a position that understands drag training as diffuse, connected to economies and very importantly community based - there are few formalised places where performers learn their drag - the discussion here is underpinned by some selective primary research. Shored-up by watching performances, connecting to the field of research available on drag performance and a level of access afforded by connections and relationships built in the community, this research uses semi-structured interviews of specifically selected drag performers spanning a range of ages and backgrounds. There is a keenness in this task to allow individuated experience for drag performers to come to the fore, rather than seek to 
homogenise a description of training. Thus, the research here looks for patterns that may exist across the experiences of drag training but does so with a resistance to homogeneity.

This homogeneity-resistant approach is manifest in and through a sensitivity to the complex and varied forms of work that arguably constitute drag performance. That is, this enquiry starts from the positon that, like any popular form, drag has a diversity of practices, some shared, some not. In addition, this approach emphasises a relationship between those practices with the form, geographical, social and temporal location of the work, and to some extent the content of the performances. Therefore, much mind is paid when talking about kings and queens together so as not to disregard the importance of the differences in relation to these factors. But of course there are limits here, the scale of this research can only serve as one element of an evaluation of drag as a performance form that connects deeply with identity, the LGBTQ+ community and individuated narratives of learning. Thus, there is little time to examine fully other forms of difference and connectedness between the kinds of work that might appear in a place like Her Upstairs. For instance, the discussion will not explore the idea that 'stylistically, drag performance was unquestionably an influence on new burlesque' (Aston \& Harris 2013 p.138) but it will bear in mind that this kind of connection through form is part of the context in which the performance practices appear.

Given the range of the kinds of work that might be seen as drag, it is understandable why academic discussion often treats drag kings and queens differently because they have different histories and traditions. Therefore, the challenge with which this paper engages clusters around how intellectual arguments might take account of these different traditions without flattening out their differences. The strategy in response here is in part to propose 
that in any discussion of drag performance it is vital to account for its deep roots in the communities that practise it. This is not to deny or reject arguments made by others that drag is mainly about gender malleability, given the number of extant academic papers and books in this area and the importance of gender discourses and politics to the lived experience of non-normative gender existing in the communities where drag is most prevalently practiced. Rather, this discussion seeks to show how the making of drag kings and queens is rooted in a minority community, a community that in some ways uses drag forms to engage with its histories and politics, which are always in relation to gender (Farrier 2016). So, although kinging and queening are a form of performance, they are also the exercise of a specific community's identity, history, politics, pleasures and entertainment - crucially in a specific time and place.

In addition to the exercise of community, drag also functions for individuals in manifold ways. Drag performers have been conceptualised and described as somehow being 'behind' the kings and queens they perform, as if the drag persona is a mask (see Escudero-Alías 2011, for instance). This paper aligns itself with a more fluid interaction of persona, identity-work, politics and community as Judith/Jack Halberstam describes:

Layering really describes the theatricality of both drag queen and drag king acts and reveals their multiple ambiguities because in both cases the role playing reveals the permeable boundaries between acting and being; the drag actors are all performing their own queerness and simultaneously exposing the artificiality of conventional gender roles. (1998 p. 261)

Thus, a discussion about drag training should wrap-in these discourses and account for the ebb and flow of energy from performer to identity to community and politics. This is important in part because this is what constitutes the forms of drag upon which this paper is 
focussed and also because for some kings and queens, the performance in some way renders queerness, it is identity work at the level of the individual and the community. Moreover, this is a local, embodied kind of politics embedded in or produced by a performance form and tradition. This is not to say that performers do not consciously make explicit political statements in their work about homophobia, for instance, they do, but even so, this serves as identity forming work, as Katie R. Horowitz notes:

Suggesting that the queens intentionally present their performance work as a form of play through which to subversively articulate a serious message about homophobia precludes reading drag as in fact more productive of the identity that authors ... claim it merely expresses. (2013, p. 311).

So, in a discussion about how queens and kings train, there should remain the understanding that the process of identity work underlies such a conversation. Of course, this may be true for any form of training, as any performer trains her/his/their identity develops as a performer. The difference here is that in the process of the king or the queen, the identity work links directly to a community identity - and, it has been argued, drag performance is a key site where queer and gay communities learn and explore their cultural and personal histories (see Farrier 2016, Hunt 2016). Although in places, some drag work may sit uneasily, kings' and queens' performances are viewed in this discussion as enactments that produce many simultaneous personal and community effects (and, for some, affects).4

As noted above, the traditions of kinging/male impersonation and queening/female impersonation have different linages and form different sets of politics in their enactments. Largely both traditions have developed in separate ways (in the West) in relation to many social, historical and economic factors (see Houlbrook 2005, and Newton 1973).5 
Contemporary kinging and queening performances function differently, the work often looks dissimilar, stimulates distinct forms of identity and desire, and articulates power in different ways. As commonly thought:

In the final analysis, however, shrouded beneath various layers of the feminine, those doing female drag ... are seeking and often exercising male authority and ultimately embodying a status of relational superiority to all present in the various venues they perform (Schacht 2002: 174).

Although this idea should be problematised in a number of ways - because, for instance, it does not take account of history of legislation in some parts of the West against men dressing in attire traditionally associated with females, nor does it account for the gradations of masculinity related to class, race or geography - the idea generally stands that drag happens in a larger patriarchal context and, of course, is subject to its structures even where they are explicitly resisted. Thus, a male identified person presenting a performance in attire associated with females is not the inverse of a female identified person performing in attire associated with males because of structural inequalities present in patriarchy. In short, to king is not the same as to queen. The discussion of their differences and similarities becomes more fluid, complex and contingent when added to this mix are considerations of different audiences for the work, the intersectional politics with which the works engage and the political energies that brings about. Likewise some of the dubiousness about queens in relation to patriarchy is reflected in discussions of some kings' work. Senelick notes that for the kings he engages with there is sometimes present elements that 'frightens and offends their female audiences' (200 p.492). This is better put by Sue-Ellen Case, who whilst reflecting on the popularisation of kinging in the 1990s, notes she was 'disturbed by performances of hyper-masculinity and violence that, in spite of claiming the transgender appearance as 
subversive, did not seem that critical of the performance of masculinity' (2009, p.11). Thus, 'drag performance... implicated as it inevitably is in hegemonic power relations' (Kurd 2009 p.42) is ensnared in patriarchy. Perhaps it is because of this complexity and diversity generated from difference in the work - not all kings perform 'men's men' (Senelick, 2000, p.492) for example - that apparently guides writers away from articulating commonalities between kings and queens, which is a manifestation of an understandable disinclination to universalise a single understanding of drag. But it is tentatively argued here that it is possible to see similarities if looked at from a specific direction: that is, rather than examine as a first term how and what drag represents, it is more useful for this discussion to look at what a drag performer does and, for this paper, how those who do it come to learn about how they do what they do.

Thus, this laudable impulse for anti-universalising results in few works that seek to speak across kinging and queening. Where there is work about kings and queens that attempts to account for their similarities, there is often present another form of universalising that this discussion does not seek to replicate - that of not attending to the local traditions and conditions in which the performance is produced (more of which below). In short, where papers attempt to account for what drag does, the discussion almost always does not engage with the local manifestations of drag. This localness is very important to the kind of work produced. For instance, I currently work in a city (London, UK) where drag in one part of the city is generally different from drag in another because it draws on a different local tradition and happens venues that have particular audiences - this is a pattern visible across many drag forms. Thus, when otherwise excellent articles about drag do not mention the locality of the work, they tend to universalise assumptions. For instance, Horowitz's discussion (2013), itself 
following an observation made by Newton (1973) many years before, makes the power of femininity and glamour in queening central to one of its arguments about the difference between kings and queens, such a position is very much situated in a US tradition, but this is not explored. Consequently, in what is otherwise an excellent article that refreshingly attempts to articulate kings and queens together, there is an under-acknowledged element that forms a crucial pillar of one of its arguments. In the UK, there is a long continuing tradition of queens who are far from the polished glamour yardstick of the US queen, a queen upon which Horowitz relies to make an argument about drag and the potential of performance studies to learn from drag knowledges.

Consequently, the challenge for any discussion of drag following this vein is to find a way of discussing kings and queens together without inadvertently universalising or erasing differences and traditions. Thus, forming a base of commonality, and chiming with Horowitz, is the awareness that when kings and queens perform they are not always manifesting a version of themselves that pre-exists the enactment. That is, there is a dynamic relationship between the enactment of identity and of character and/or persona, or put in other terms: there is a vigorous relationship between performance and performativity in drag shows. 6 Others note this too and see drag as deeply connected with identity work in a multiplicity of ways (Langley 2006, Siegel 2008). This is a key point of connection that allows for a diversity of performances, specifically located geographically and temporally, and that does not seek to universalise a position in relation to the work that relies on what it looks like or re-presents. A turn to the local (be that geographic, temporal, historic) should be present so as not to allow the assumption that a small town in the UK does the same kind of drag as a small town in 
New Zealand (for instance) because it is connected to its social context which changes over time in different geographical locations.

\section{Mothers, Fathers, Uncles, Daughters, Sons, Nephews.}

Looking now to a discussion of drag training, other similarities between kings and queens become apparent, connections that can resist the collapse and erosion of traditions as described above. This 'training' is not formalised or structured in coherent ways and there is very little by way of understanding of methodology in this form of schooling. There is no system of training per se, but there are similarities across specific geographical and temporal locations in which kings and queens train.

For instance, drag performers often refer to their drag mother, father or uncle as key in the development of their drag work. The role of the mother or father is to help a new drag performer find a persona and learn the skills and techniques of the markers of drag. In a time, pre-internet 2.0, this parental figure would typically be found within a local community normally a bar or a nightclub where performers did their drag. Thus, younger kings and queens learned their skills from local traditions formed in local communities. Mothers and fathers might give a new drag performer advice on the look of the king/queen, the structure of a performance, adding material to a repertoire whilst also passing on an understanding of investing in a community of drag. If that younger drag king or queen stays in the drag world, then it is likely they too will become a drag mother or father as they develop their own work. Thus, in this community sisters and brothers, mothers and fathers, uncles and nephews are 
doing it for themselves - they are in an embodied sense recirculating performance knowledges themselves generated within the community.

This is a form of passing on and recirculating training knowledges reflects what Alyson Campbell is developing as 'feral pedagogies' (2017). Campbell's work focusses on the manner in which queer communities, particularly indigenous communities in Australia, circulate knowledge and education about HIV and AIDS. Such a shape - feral pedagogies, an ad hoc (or locally organised) education experience within a specific community by that community's members - can be observed reflected in an historical sense across present and past queer communities (Houlbrook 2005, Bauer and Cook 2012). This kind of exchange of performance training and skill in what has an appearance of a family structure (mothers and daughters, fathers and sons, uncles and nephews) might form a feral pedagogy, whilst also mirroring family exchanges in other popular forms of performance, particularly circus entertainment families, who reproduce their skills within a family set up (indeed at the moment in London there is a drag collective, known as the Family Fierce, who play off this idea). These flows of skills are specifically located. Thus, if a new king or queen becomes a drag-daughter or nephew or son, in a context in which lip-synching is prevalent, it is likely that they would structure their acts likewise, or at least the acts will in some way be imbued with this sense. Similarly, if a drag mother or father has roots in popular variety or music hall, the work is likely to be imbued with this sense too (even though, of course, the new king or queen will make their act their own in some way).

For instance, drag queen Gale Force, performer Mark Edward, spoke to me about his training gained when he was a mid-teenager in the 1980s in a working class area of the north of 
England, in a place he describes as dominated by "pits, pies and pubs".7 When he grew up Mark was strongly drawn to a number of drag performers he saw on the television in the 1970s (in particular he mentions Dick Emery).8 Fuelled by this interest, Mark made his first forays into the drag scene with those 1970s television drag characters as inspiration, on the scene Mark learnt his skills from drag queens working in what he calls the Fun Pub circuit (where Mark was given his first drag name of Tallulah Tongue). This environment was mainly populated by straight punters and was a place where working class culture was most prevalent and mirrored Mark's home life. Mark started his training as a dresser for Chris D'Bray - a queen still working the circuit in Wigan and the surrounding areas today - and also worked as Chris's dancer on occasion. Chris served to help Mark learn the skills of drag. In particular Mark notes that Chris taught him the key skills of drag common to queens at that time - such skills as shading and contouring in makeup, body padding, tucking, frocks, learning numbers and wig-styling.9 In interview Mark notes that there was no internet at this point and the only way that this information was available to him in his geographical and historical context was through this community, and in particular his drag mother. As this exchange was progressing young Mark learned the skills and rigour of the performance form, however, he also learned about local drag traditions that were outside of the direct drag skills, particularly the structure of short form performance (in itself referencing North Club traditions) and how these related to representations of class, which was to become very important in Mark's later work.

In this community, as in many others, Mark learned and perfected his drag skills in a commercial environment. This is not a performance environment connected to arts funding structures. Up to now, this discussion has focussed on the community in which drag most 
often emerges, but as the discussion with Mark reminds, there is a connection between the community and the commercial drive of the environment that affords the opportunity to find a drag mother. This commercial environment has an impact on the kinds of drag acts that develop within it. Such an influence is not only present in the sense that commercial premises form the space in which Mark was able to meet his drag mother and thereby influence in some way the terms of that meeting, but may also have an impact on the kinds of material that might be produced in the fun pub. Newton (1973) in her ground-breaking study of drag queen communities notes this connection in the US context, where she relays the idea that lip-synching as a drag performance technique may have come from a need to reduce the cost of performance in the light of smaller audiences after homophobic legislation influenced audience attendance - that is, the record act being cheaper than hiring a house band. Likewise, in Mark's case the kind of work he was learning at that point fitted the kinds of audiences that spent money in the pub, as such the work was related to such economies (Mark agrees that had he an urge to perform some light opera, this might not have gone down so well on a Friday night in his small working class village outside Wigan, UK).

Indeed, the work that is produced in drag often relates to popular culture per se, particularly through contemporary celebrities, pop music and often past popular culture that resurfaces as a love of kitsch in a number of queens' work. This relation to the popular and economies attaches directly to the content and form of the work. Given that drag is most often short form, it is frequently structured with a set up/pay off organisation that determines to some extent the way that the training happens. To learn this structure Chris sent Mark away to learn numbers by audiocassette that Chris would critique when Mark returned. This forms a 
kind of local rigour that drag demands and that Mark took forward when he left to formally train in dance and performance art at university.

By 2012 Mark's new drag persona, Gale Force, appeared in a piece entitled Council House Movie Star, in a gallery space in Liverpool (work this time developed with external arts funding). The space comprised a replica council house (with some surprise spaces accessed through unexpected places) that Gale lived in for three weeks, living her own run down, 1970s' inflected life.10 Gallery attendees/audiences could wander around the instillation at their leisure, sometimes Gale would ignore them and be in a world of her own, sometimes she would interact with attendees - particularly where they fitted into the aesthetic (she interacted with visitors who appeared to come from the local housing estates, for instance). Interestingly at one point in the instillation Gale was visited by Chris D'Bray, also in drag, and they performed some of the old routines from their time together in the 1980 s and $1990 \mathrm{~s}$ (see Figure 1). This work had a long-form improvisation quality about it and could most certainly be related strongly to immersive performance and performance art traditions, yet the piece still contained much of the energy and aesthetic of the fun pub work.

\section{INSERT FIGURE 1}

Figure 1. Chris D'Bray (right) visits Gale Force (Mark Edward, left) at her instillation Council House Movie Star, Liverpool, UK 2012, photographer: Helen Newall.

So, although Gale Force took this work to a new place, Mark's training was in some ways quite traditional in that he found a drag mother and from her learned the techniques of drag. And although Mark then went on to develop Gale Force after being acquainted with performance 
art via postmodern dance, the muscle memory of that early training still appears in the later work. Indeed, Council House Movie Star consciously replicated the sensations of the 1970s with some of the routines of the 1980s (themselves with much earlier roots). For now, in this discussion Mark/Gale serves as a working class Northern UK sited exemplar of how training might have been experienced pre-internet. There are younger queens who had a different type of experience, still related to the traditions of the drag parent but also influenced by emerging technologies.

Moving to another queen, Mercedes Bends (the drag persona of Ben Gledhill (See Figure 2)) and a number of the same things appear in his preparation that were apparent in Mark's, except that Ben's training happened in a time when the internet was further developed but not to the extent that it has currently in regard to materials available for learning about drag, more of which below.11 Ben recalls that as he was developing his drag, it was only 'for a bit of fun', and that he understood he was 'doing it all wrong' in the beginning. Drag for Ben, at the start, was play. Mercedes, however, did not have a drag mother in the same way that Gale Force did, rather Mercedes already had knowledge of some skills because Ben had previously trained as a make-up artist. Yet, despite this, influential in Ben's development was a queen called Rose, known out of drag as Ron Martin, Ron was a much older drag queen, who cut his teeth in the 1940s. Ron encouraged and developed Ben's work, particularly by entering him for a drag competition. Mercedes' work is traditional in that it references short form performance's setup/payoff structure, but is often not lip-synched, it is sung live, choreographically driven, with 'eye-candy' dancers and an encouragement of a raucous atmosphere (this is a kind of drag that might be deeply connected with punk). In the environment of the competition Mercedes networked and formed other mother/daughter- 
like relationships with queens who were able to show him what he calls some of drag's 'trade secrets'. In part this meant he was shown to out of the way costumiers who could make frocks for him in the style that suited Mercedes, and also how to style and choose good wigs.

\section{INSERT FIGURE 2}

Figure 2, Mercedes Bends, Brighton 2011, photographer: Stephen Farrier

The environment of drag competitions, which are very popular with the community and with the general public (popular competitions in the UK are, for instance, Drag Idol, which was the competition that Ben was entered for, and Man Up, and the award winning RuPaul's Drag Race, is broadcast internationally, which is essentially a long drag competition) returns the discussion to economies in relation to drag training. Such competition in the UK is commercially driven with a community edge (Drag Idol, Man Up) and as Ben notes, older queens will teach younger queens through a family structure or simply helpfully critiquing each other's acts. But Ben was aware from the beginning that drag is a commercial market in which queens might be vying for the same work. Yet, even though this is the case, queens still support each other and see the community as important; there is commercial altruism at play at some level. And given that drag performance is in some way the productive enactment of queerness and located in a specific community, it has shown this philanthropic impulse to be an important part of its presence, thus drag has been a key player in the rights struggles for gays and especially played a crucial role in HIV and AIDS awareness during the crisis years in the US and UK, and continues to do so in parts of the world where sexual health education is vitally pressing. 
These competitions, separately aimed at kings or queens, are frequently a way for new drag performers to develop and explore their personas on stage with a generally supportive audience. For some performers, kinging competitions are a complement to other performance work. For instance, johnsmith (see figure 3) a king persona of Eleanor Fogg, found herself in the kinging scene 'by accident' and notes that she is as happy in the cabaret scene - indeed, she may well be more seen in that scene and notes that she kings only in the sense that it is part of a larger repertoire of personas (which are cross-gendered and crossspecies).12 Whilst studying for an MA in scenography, she made a video work, uploaded it to the internet and through that post, secured professional bookings. In the piece, she performs a lip-synch to a slowed down pop song whilst shaving her unbound chest. The work that johnsmith does is informed by an understanding of lighting, design and performance that has some roots in a formal training institution - but, crucially for this discussion, elements of the work are present because johnsmith has experienced learning through the communities where he is performed. In particular, Eleanor garnered support from individuals on the scene in part since she won a popular kinging competition and also because she moves in circles with other drag artists. Interestingly, in interview she notes that she did not have the usual father/son, uncle/nephew familial relationship described by other drag performers, but a key influence was a drag queen (a member of the Family Fierce). This individual amongst others, helped Eleanor with some of the skills of drag in informal ways - often through observation and helping Eleanor problem solve when, for instance, she was trying to replicate a particularly changeling look, or conquer a tricky bit of shading/highlighting. She relays that this kind of support/learning network often gives time and advice freely, but also people working on the scene understand that drag is expensive, consequently she notes that many carry a kind of duty to employ members of the community who are brilliant in particular 
production areas. Eleanor adds to this idea that in this economy, autodidactic qualities are often in play, individuals may self-learn the operation of sound equipment, cue a show, or construct a costume, for instance. Making skills, Eleanor observes, can heavily influence the kinds of practice that goes on - often a newly developed skill, or a skill in the process of acquisition, forms the basis of an act. Or, a desire to do a particular thing in performance drives auto didacticism.

\section{INSERT FIGURE 3}

Figure 3 johnsmith, photographer: Julia Shoenstaedt.

In a broad-brush stroke way, johnsmith appears in some sense as a new form of performer, who absolutely respects the histories and politics of kinging, whilst also being proud to be considered a king and work in that scene but who in part used web 2.0 to discover how her personas are developed and rendered. As she notes, it is easier to control an image on video, if not its subsequent spread and use. Eleanor is influenced by other technologies too, at the time of writing she is

working with a DJ controller which enables the audience to change the speed of my lip-synch by touching a wheel on my stomach. This was an idea I had but didn't know if/how it was possible - [I] did research and talked to people, borrowed and tried some things, found the right equipment - and eventually it was. And in fact now using that controller to control my whole show'.13

johnsmith is not a solidified persona and plays along lines of plurality. Eleanor notes that johnsmith does not have a singular gender 'and so it wouldn't be right to call them a 'king' full time'. They are a king more akin to the aesthetic of David Lynch than to a cookie cutter Elvis impersonator, who might get a party started, and was formed both through the means of 
(now) readily available materials for making work along with skills acquired through higher study in combination with hybrid forms of drag performances produced through this connection with web 2.0.

Both Ben and Mark note that in the past few years in the UK, a new breed of queen is emerging, one who has less connection with the mother/father structure of the past, but one who has access to a large amount of information about drag on the net. Indeed, some of these queens note that 'YouTube was my drag mother' (in Farrier 2016). Whilst I have argued elsewhere (Farrier 2016) that this non-local form of learning might appear to undo some of the traditions of specifically located drag, given that large amounts of on-line material presents drag from a US perspective and tradition, the younger performers who adopt it are doing so with a knowingfulness perhaps brought about by the local context in which they make and show work. That is, in order for it to have some kind of resonance and relevance for the audience it should in some way connect to the locality in which this happens.

As younger performers use the internet to develop their skills and learn to paint, blend, pad and lip-synch from other people across the world, it is easy to look to what is missing in these forms of training. Yet, it is also worth balancing this position with another that looks now to the diversity of drag and drag-like material circulating in the pubs and clubs post web 2.0. It is now possible to see a queen with a sparkly beard performing femininity mixed with an animal, or to see a king who does not bind, but equally sports magnificent facial or malepatterned body hair. Although in the UK it is very easy to read the now older traditional style drag as somehow superseded by this new more internationalised form, the new form often embraces the traditions of the older style - even when this is not a local feature of drag. So, 
for instance, it is possible to see a queen in the UK enacting moves which reference the "ball scene' in the US - there is no local tradition of the ball scene in the UK that matches the US, in part because it is so firmly rooted to a specific location, history and community in parts of the US.14 However, now this forms part of the lexicon of drag in the UK scene too.

The ball scene is a specifically located community that has performance at its heart. Marlon M Baily describes the scene thus:

the "house/ball community," is a community and network of Black and Latina/o women, men and transgender women and men who are lesbian, gay, bisexual, straight and queer. The Black and Latina/o queer members of this community use performance to create an alternative discursive terrain and a kinship structure that critiques and revises dominant notions of gender, sexuality family, and community. (2011:367)

The ball community has a structure built around 'houses', which are groupings of individuals, often referred to as family, that compete with each other at gatherings/balls in various dance and movement categories. In those communities, there are a complex set of dance and dancelike movements (generally/collectively referred to as runway, or walking, which is also a synonym for competition) and a lexicon of slang terms, some of which are shared with drag performers. The most visible aspect to those outside the community are the drag balls, which centre on competitive performance and its community building effects. The community, however, through its refusal of normative modes of kinship, is structured as a complex fluid and dynamic social grouping of people who do not present their selfhoods in normative ways. The roots of the scene are planted in a protest against the consistent disregarding of black queens at drag pageant competitions in the 1980s.15 
However, when drag performers use slang, or movement styles from the ball scene without engaging with the complexity or meaningfulness of those choices, it can be read and experienced as a form of colonisation - given the resonance of the ball scene to the Black and Latina/o communities within which it is produced, but in the process of translation from the US to the UK scene it is in some way transformed. What has come from the ball scene is a particular set of gestural codes, dance moves and slang as well as the inclusive community building energy associated with it. The ball scene too, like drag, has specialist community performance knowledges embedded in their contexts - for instance in the ball scene there is a common understanding of 6 genders (Bailey 2011) - which can be difficult to grasp without such knowledges because of their specificity and locateness.16 Some of these diversityfocussed attributes are replanted in the UK scene, and, consequently, rejected by that openness are some traditional forms of pub drag where humour is based on racism, homophobia (often towards lesbians) and in particular, a general misogyny.

Thus in process of the diversification of sources of information about drag that younger kings and queens use to develop their work and hone their craft, the lexicon in the drag scene in the UK has expanded. However, even with all this information - the thousands of videos available for guidance about how to be a king or a queen - still the relation of community persists. Eleanor is keen to point out that she learned her skills through a commingling of her formal training and web 2.0 as well as connecting deeply with the community within which she works. The way I have represented her journey here may not reflect the complexity with which these threads are entangled. For instance, she learned her lip-synch both through the web, watching performers live, and working hard alone to perfect the skill. Often, as noted by Ben, younger queens look more polished when they first attempt drag in a performance 
environment, but they still require coaching and guiding about their performance skills and talents. That is, the 'tricks of the trade' to which Mercedes refers are now an open secret available to anyone with an internet connection. What is less available are the community networks that develop and enhance the work for the drag-baby and these may account for a local infusion in the work. Rather in the same way that queer theory critiques discourses of the apparently powerless in a global/local binary (Binnie 2004, Spurlin 2006) asymmetrical power relationships imply a lack of agency in the 'receiver' of globalisation, but younger queens are taking this non-local (global/international/transnational) material and making it local - this rendering is through the crucible of training that is local in its energy. As ever, there is a politics here - young, white well educated queens claiming that the ball scene is their scene too smacks of colonisation and should be unpicked.

\section{Possible futures}

In part, as web 2.0 queens develop their families, the politics of colonisation filters though the work. So it might be that in a death drop, or a vogueing section of a drag performance (both movements in ball scene walking, which require great skill and, in places, courage) there is some acknowledgement of the source of the move and recognition of the imbalance of power relationships manifests in the performance as a cornerstone of the work. That is, some queens acknowledge their sources in their performance. In addition, as the older queens develop, they too carry on traditions in new ways. Mark Edward attracted international press attention, for instance, when he added a module in drag performance to the degree on which he teaches.17 This module develops not only the performance aspects of the work - the skills of walking, lip-synching, costume etc., but also the cultural and critical discourses that have emerged from and around this work. Therefore, students studying this particular module 
have not only an intellectual sense of how the work functions in terms of gender, queerness and community (for instance) but they also have an embodied sense of drag as making queerness. Thus, Gale Force has in some sense become a university drag mother who can grade her offspring using university-validated learning outcomes, expecting them also to cite their sources in their work, whilst likewise giving sage advice about a lipstick colour, or the arrangement of facial hair.

Speaking of drag kings and queens together is the writing out of a political inclination, one that serves to look to what coheres these performances and performers in terms of a functioning community. Although, as it has been noted, the audiences and traditions of kinging and queening are different and the effects in the performance room follow this difference, there are places where kings and queens speak similar languages - how they learn their chops is one place where there is potentially a shared vocabulary. Here there is no desire to collapse the differences noted above, nor to minimise or belittle the inequalities manifest in the work because it sits in our patriarchy, which does not only manifest in impactful material ways, but also in other less visible ways too. Thus, it is clear that there is other more detailed and specific academic work yet to do. Nor is there a desire here to only see community in a rosy glow - community can also be restrictively exclusive and policing rather noting that interactions with drag performance in a specific community appears to be growing (if the many millions of sites, posts, blogs, video tutorials is an indication of popularity) and that growth might in some way open other discussions for the community, clustered around how it does its performance, politics and has fun without recirculating injurious images/discourses by resisting normative calls to gender-based behaviours and 
identities. And, of course, such newly growing diversity helps the community see ever more fabulously mixed-up creations.

1 I am indebted to Joseph Parslow, one of the co-owners of the bar (along with Meth, the drag queen), for discussing with me the work in the bar and the range of performers present there. 2 For instance, drag kinging as subject matter often does not get the press attention of drag queening, but kinging has appeared in articles in The Independent and The Guardian in the UK and in popular internet outlets such as the BBC Newsbeat service (a youth news outlet), and Buzzfeed a popular youth orientated internet outlet (see Buzzfeed 2015, Holden 2015, Stephenson, 2016, Williams, 2013).

3 Web 2.0 is generally associated with user-generated content and the rise of social media. 4 See Stephen Greer's discussion of drag and camp identities uneasily sitting in gay politics' presumed inclusivity in his discussion of 7:84's production of seXshunned in 2004 (Greer 2012, pp.83-86).

5 In particular, Houlbrook explores the relationship of the class and economy to drag balls in London 1918 - 1957.

6 Although outside the range of this discussion, I am referring here to Butler's (1990) description of Performativity. Performance and performativity have a particular resonance in queer performance, see Meyer and King (2010) for a re-reading of the parsing of performance and performativity.

7 I interviewed Mark/Gale in August 2016.

8 Dick Emery (1915-1983) was a British comedian, most known for his popular television series that ran from 1963-1981.

9 Shading and contouring for kings and queens in a process though which faces are shaped with make up to show them as more feminine/masculine as popularly thought - a time consuming process that is often referred to as 'painting' or to 'beat your face'. Padding for queens is a process of shaping parts of the body through padding to create a silhouette associated with feminine body shapes as conventionally conceived. There is less body padding for kings, but they often 'pack', which is likewise padding/a prosthetic penis. Tucking for queens is a process of arranging the penis and testicles to present a flat pelvic area (a popular process involves pushing the testicles into a body cavity known as the inguinal canal and taping the penis between the legs). Binding for Kings is the process by which breast tissue is pressed flat against the chest using a strong elastic binder (though there are other techniques such as compression shirts and taping).

10 Council House is UK parlance for local government social housing.

11 I interviewed Ben/Mercedes in August 2016.

12 I interviewed Eleanor/johnsmith in August 2016.

13 Personal correspondence with Elanor Fogg, February 2017.

14 I do not wish here to ignore the balls that have happened and continue to happen in the UK (particularly in Manchester, Liverpool, Glasgow and London) but the UK scene does not match the history of the US's legendary houses.

15 The early development and formation of the scene is chronicled in Jennie Livingston's 1990 film Paris is Burning.

16 Bailey (2011) refers to these genders as: "(1) butch queens, who are biologically born male who identify as gay or bisexual and are and can be masculine, hypermasculine or feminine; 
(2) femme queens (MTF), who are transgender women or people at various stages of gender reassignment - through hormonal and/or surgical processes; (3) butch queens up in drags, who are gay men who perform drag but who do not take hormones and who do not live as women; (4) butches (FTM), who are transgender men or people at various stages of gender reassignment or masculine lesbians or woman appearing as men regardless of sexual orientation (some butches use hormones and have surgical procedures to modify their bodies; (5) Women, who are biologically born females who identify as lesbian, straight, or queer; and (6) men/trade, who are biologically born male who are straight-identified men." (pp 370-1)

17 The module gained press attention from broadsheets, such as The Telegraph in the UK, and the popular press such as The Daily Mirror and The Sun (also in the UK), The Times Higher Education, as well as popular international websites such as the BBC, Huffington Post and Pink News. It was also covered by many other local and national news outlets too numerous to list here.

References.

Aston, E. \& Harris, G. 2013. A good night out for the girls; popular feminism in contemporary theatre and performance. Basingstoke: Palgrave.

Bailey, M. M., 2011. Gender/radical realness; theorizing the gender system in ballroom culture, Feminist Studies. 37 (2), 365-86.

Bateman, D., 2002. Performing femininity on stage and off, Canadian Theatre Review, 109, 38-41.

Bauer, H., \& Cook., M., eds., 2012. Queer 1950s, rethinking sexuality in the postwar years. Basingstoke: Palgrave.

Binnie, J., 2004. The globalization of sexuality. London: Sage.

Butler, J. 1990. Gender trouble, feminism and the subversion of identity. London: Routledge. 
Campbell, A., \& Gindt, D., eds. 2017 (forthcoming). HIV and AIDS in twenty-first century theatre and performance: an international collection. Basingsoke Palgrave.

Case, S-E. 2009. Feminist and queer performance, critical strategies. Basingstoke: Palgrave.

Edgar, E.A., 2011. 'Xtravaganza!: drag representation and articulation in RuPaul's drag race', Studies in Popular Culture. 34 (1), 133-46.

Escudero-Alías, M., 2011. Ethics, Authorship, and the representation of drag kings in contemporary US popular culture, The journal of popular culture. 44 (2), 256-73.

Farrier, S., 2016. That lip-synching feeling: drag performance as digging the past. In A. Campbell and S.Farrier, Eds. Queer Dramaturgies: international perspectives on where performance leads queer. Basingstoke: Palgrave, 192-209.

Greer, S. 2012. Contemporary British queer performance. Basingstoke: Palgrave.

Halberstam, J., Female masculinity. Durham: Duke University press.

Holden, S., 2015. Drag kings of the UK: the women who perform as men

Newsbeat 18 May [online] http://www.bbc.co.uk/newsbeat/article/32764145/drag-kings-ofthe-uk-the-women-who-perform-as-men [accessed 30th Aug 2016].

Horowitz, K.R., 2013. The trouble with "queerness": drag and the making of two cultures. Signs: journal of women in culture and society, 38 (2), 303-26.

Houlbrook, M. Queer London: perils and pleasures in the sexual metropolis, 1918-1957. Chicago: University of Chicago press. 
Hunt, R. J., 2016. Queer debts and bad documents: Taylor Mac's young ladies of. In A. Campbell and S.Farrier, Eds. Queer Dramaturgies: international perspectives on where performance leads queer. Basingstoke: Palgrave, 210-243.

King, T. A., and Meyer, M., 2010. In defense of gay/performance. In M. Meyer, ed. An Archaeology of posing, essays on camp, drag, and sexuality. US: Macater, 151-81.

Kurd, M. 2009. Lesbian Versions of the Female Biography Play: Emma Donoghue's I Know My Own Heart and Ladies and Gentlemen. In David Cregan ed. Deviant Acts: Essays on Queer Performance. Dublin: Carysfort Press, 37-53.

Langley, C., 2006. Borrowed voice: the art of lip-synching in Sydney drag. Australasian Drama Studies,.48, 5-17.

Newton, E., 1979. Mother Camp, Female Impersonators in America. Chicago: University of Chigago Press.

Paris is Burning, 1990. Film. Directed by Jennie Livingstone. USA: Miramax.

Siegel, M., 2008. Vaginal Davis's gospel truths. Camera Obscura 67, 23 (1),151-9.

Senelick,, L., 2000. The changing room: sex, drag and theatre, London: Routledge.

Shapiro, E.., 2010. The impact of race on gender transformation in a drag troupe. In S. Hines, and T. Sanger, Eds Transgender Identities, Towards a Social Analysis of Gender Diversity. London: Routledge,153-69. 
Spirlin, W., 2006. Imperialism within the margins - queer representation of the politics of culture in Southern Africa. Basingstoke: Palgrave.

Stephenson, M., 2016. Put a sock in it - all rise for the UK's drag kings. The Guardian 23 June [online] https://www.theguardian.com/lifeandstyle/womens-blog/2016/jun/23/put-a-sock-in-itall-rise-for-the-uks-drag-kings [accessed 30th Aug 2016].

Taylor, V. \& Rupp, L. J. (2005) When the girls are men: negotiating gender and sexual dynamics in a study of drag queens. Signs, New Feminist Approaches to Social Science Methodologies. Vol. 30 (4), 2115-39.

Williams, H., 2013. Man up: the world of the 'drag king'. Independent, 2 March [online] http://www.independent.co.uk/arts-entertainment/theatre-dance/features/man-upthe-world-of-the-drag-king-8513984.html [accessed 30th Aug 2016].

Women get transformed into drag kings for the first time., 2015. Buzzfeed [online] https://www.buzzfeed.com/jazminontiveros/what-happens-when-women-gettransformed-into-drag-kings-for?utm term=.cg7xWBxoB\#.etOEXVEJV [accessed $30^{\text {th }}$ Aug 2016]. 